\title{
Job Satisfaction in Primary Health Care Physicians in Selected Family Medicine Centers in Cairo
}

\author{
Rania Adel Morsy, Mohamed A Momen², Hasnaa A Abouseif ${ }^{2}$, Mostafa El Hosseiny² \\ ${ }^{\mathbf{1}}$ Family medicine resident at new Cairo district, ${ }^{\mathbf{2}}$ Department of Community, Environmental \\ and Occupational medicine, Faculty of medicine, Ain Shams University.
}

Received: September, 2017 Accepted: November, 2017

\begin{abstract}
Background: Job satisfaction is the affective orientation that an employee has towards his work. Greater physician satisfaction is associated with greater patient adherence and satisfaction. Objective: this study aimed at assessing the level of job satisfaction among PHC physicians in new Cairo district, and to assess the potential factors affecting job satisfaction among them, also to measure the work related affective wellbeing among them. Methods: A descriptive cross-sectional epidemiological approach was adopted using two interview questionnaires; Job satisfaction survey (JSS) and Job-related affective well-being scale JAWS. Results: Job dissatisfaction was encountered in $47.6 \%$ of physicians. Pay, fringe benefits and contingent rewards were the most frequently encountered domains with which physicians were dissatisfied. Married physicians, years of experience 5-15 years had higher JSS compared to single physicians and fewer years of experience. Also JAWS score was a significant independent variable affecting JSS score. The affective well-being score ranged from 45 to 74 with mean \pm SD $61.6 \pm 5.5$, and it was affected by age, with no significant effect of other demographic characteristics. Conclusion: It is highly recommended to improve working conditions, payment and provision of better opportunities for promotion of PHC physicians to subsequently improve their subjective wellbeing and their job satisfaction which in turn will improve their performance.
\end{abstract}

Key words: job satisfaction, affective wellbeing.

Corresponding author: Rania Adel Morsy E-mail:

\section{Introduction}

Work is more than a mere mean of subsistence, it bestows on one personal identity, self-actualization and social image. ${ }^{1}$ Job satisfaction is an attitude that is simply how content an individual is with his or her job; whether he or she likes the job or not. ${ }^{2}$ It is a very popular socialpsychological managerial term and has been measured both globally (i.e. overall satisfaction) and dimensionally (e.g. salary, inter-personal relations, professional opportunities and organizational practices ${ }^{3,4}$, that declares the association of job dissatisfaction with burnout, absenteeism, and turnovers, and why that makes it a main concern for employees, employers and human resource agencies. ${ }^{5}$ Affective wellbeing refers to feelings about either life in general (i.e. context-free), or affect in relation to a specific domain (i.e. job-related and facetspecific) (Hosie \& Sevastos, 2010). ${ }^{6}$ 
Context-free and facet-specific affective wellbeing have different predictors. Facetspecific affective wellbeing includes factors such as pay, responsibility, colleagues, supervisors, working conditions, promotional prospects, and security of employment, the organization as a whole, and the kind of work undertaken. It can be measured in relation to the work domain (Hosie \& Sevastos, 2010). ${ }^{6}$ Context-free affective wellbeing includes factors such as satisfaction with self image, physical health, and social and home life which are known to contribute to affective wellbeing (Hosie \& Sevastos, 2010). ${ }^{6}$

Measures of affective well-being are amongst the most important indicators of psychological well-being. Job related affective well-being is important for a healthy life and job satisfaction for all individuals, including physicians who, are most often compromised (Daniels, 2000). ${ }^{7}$ The job satisfaction of the primary health care physician is a critical factor for health systems because the primary care level is responsible for providing medical care to a greater proportion of the population than any other care level and it is related to the quality and efficiency of the care given. ${ }^{8}$ The perception of health practitioners may affect the way that they treat patients both medically and personally ${ }^{(8)}$. Primary health care physicians usually live among their patients, deal with $90 \%$ of health care problems and need to address them in global terms, specifically the physical, psychological and social dimensions ${ }^{(8)}$. The role demands high levels of skill and motivation, yet despite this, family physicians are often perceived as second rank doctors by medical students, administrators and other specialists. Hence, many family physicians and general practitioners (GPS) feel both geographically and professionally isolated, with a demanding job and unsatisfactory status. ${ }^{8}$ In Germany; $64 \%$ of physicians said that they were satisfied or very satisfied with their job overall. There were particularly high rates of satisfaction with patient contact (91\%) and working atmosphere $(87 \%)$. In contrast there were high rates of dissatisfaction with administrative tasks (75\% dissatisfied). ${ }^{9}$ In Pakistan the overall satisfaction rate was $41 \%$ only, while $45 \%$ were dissatisfied, and $14 \%$ of physicians are highly satisfied with their jobs. ${ }^{10}$ In Saudi-Arabia, a study done in Al-Madinah-Al Monawarah shows that the overall mean score of physicians satisfaction was $65.5 \pm 12.8$ and that for nurses is $61.2 \pm 12.3 .^{11^{-1}}$

Gadallah and co-workers in Egypt reported that relationship with patients, their career as health care givers have been the most important satisfaction factors, but income and work resources represented the least satisfaction items. ${ }^{12}$ Another Egyptian study showed that the total mean score percent of job satisfaction among physicians was 56.8\%. Relationship with colleagues represented the domain with highest percentage of satisfaction, while the domain of salaries/incentives represented the lowest satisfaction. ${ }^{13}$

Studies on this subject remain scanty in Egypt where shortage of health manpower and high burden of the disease are prevalent. Also, medical professionals are seen as super-humans and the expectation of self-sacrificing is higher than in other professions. Aim: The study was conducted to determine level and potential factors affecting job satisfaction and work related affective wellbeing among PHC physicians in PHC centers of New Cairo district. 


\section{Methods}

Type \& place of the study: A crosssectional study included physicians working in 4 primary health care (PHC) centers in New Cairo district. Time of the study: The study was conducted over three months from July to September 2016. Study population: Physicians working in the four PHC centers. Sample size: A sample size of 170 physicians was calculated depending on prevalence of physicians satisfaction to be $50 \% \pm 7 \%$ with $95 \%$ confidence interval using $\mathrm{P} \& \mathrm{~S}$ program. Sample type: a convince sample was taken from the four centers. Study setting: The sample was collected over non fixed three days per week, for three months, taking into consideration day and night shifts. The actual total number of all physicians working in the four PHC centers was 282 . Total number of 170 was interviewed from all 4 centers nearly equal.

Study tools: Job satisfaction survey (JSS) questionnaire included 36 questions $^{14}$, and Job-related affective well-being scale (JAWS) questionnaire with 20 questions ${ }^{14}$ with Instructions for Scoring developed by Spector. Both questionnaires were translated into Arabic and revised by the researchers. Some questions were added asking about Socio-demographic data as age, sex, marital status, income, highest qualification level and residence.

Data management: Data was collected, coded and entered then analyzed using SPSS program version 20. Quantitative data were presented as mean and SD. Qualitative data were presented as number and percentage. Independent samples t test was used to compare quantitative data in two different groups. One way ANOVA test and Post-hoc test was used to compare quantitative data between more than two groups. Regression analysis was done to identify independent factors affect job satisfaction and affective wellbeing.

\section{Ethical considerations:}

Official approval was obtained from $\mathrm{MOH}$. Also, informed oral consent was obtained from the physicians after informing them about the objectives of the study and confidentiality of data was ensured by making the questionnaire anonymous.

\section{Results:}

The study included 170 physicians working in four PHC centers in New Cairo district; most of them $(49.4 \%)$ were in the age group 25-30 years, females $(91.8 \%)$ and married $(84.7 \%)$. Less than half of them had a postgraduate degree $(41.2 \%)$ and $64.2 \%$ with less than 5 years of working experience. The majority of studied physicians $(48.2 \%)$ had a monthly income between 2000-4000 LE and only $14.7 \%$ had monthly income more than 4000 LE. (Table 1)

The total job satisfaction score of studied physicians was $108.8 \pm 16.6$ with other job satisfaction subscale score (Table 2). The highest satisfaction rate was for physician satisfaction for relation with coworkers $(61.2 \%)$ and the lowest satisfaction (0.6\%) was for pay (Table 3).

Married physicians with years of experience $5-15$ years had higher JSS compared to single physicians with fewer years of experience. Also JAWS score was a significant independent variable affecting JSS score (table 4).

Regarding factors affecting work related affective wellbeing score, multivariate regression analysis revealed that physicians age above 40 years and more years after graduation were significant independent variables affecting work related affective wellbeing score (Table 5). 
Table (1): Demographic characteristics of studied group

\begin{tabular}{|c|c|c|}
\hline & & $\mathrm{N}(\%)$ \\
\hline \multirow{5}{*}{ Age (years) } & $<25$ & $9(5.3)$ \\
\hline & $25-$ & $84(49.4)$ \\
\hline & $30-$ & $27(15.9)$ \\
\hline & $35-$ & $13(7.6)$ \\
\hline & $>40$ & $37(21.8)$ \\
\hline \multirow{2}{*}{ Gender } & Male & $14(8.2)$ \\
\hline & Female & $156(91.8)$ \\
\hline \multirow{3}{*}{ Marital status } & Single & $11(6.5)$ \\
\hline & Married & $144(84.7)$ \\
\hline & Divorced/widow & $15(8.8)$ \\
\hline \multirow{4}{*}{ Education } & Bachelor & $100(58.8)$ \\
\hline & Diploma & $35(20.6)$ \\
\hline & Master & $30(17.6)$ \\
\hline & Fellowship & $5(2.9)$ \\
\hline \multirow{5}{*}{ Years after graduation } & $1-$ & $40(23.5)$ \\
\hline & 5- & $66(38.8)$ \\
\hline & $10-$ & $20(11.8)$ \\
\hline & $15-$ & $15(8.8)$ \\
\hline & 20 or more & $29(17.1)$ \\
\hline \multirow{5}{*}{ Years of working experience } & $1-$ & $42(24.7)$ \\
\hline & $5-$ & $67(39.4)$ \\
\hline & $10-$ & $16(9.4)$ \\
\hline & $15-$ & $15(8.8)$ \\
\hline & 20 or more & $30(17.6)$ \\
\hline \multirow{3}{*}{ Monthly income (LE) } & $<2000 \mathrm{LE}$ & $63(37.1)$ \\
\hline & $2000-4000 \mathrm{LE}$ & $82(48.2)$ \\
\hline & $>4000 \mathrm{LE}$ & $25(14.7)$ \\
\hline
\end{tabular}

Table 2: Job satisfaction score and its different subscales and work-related affective wellbeing score:

\begin{tabular}{|l|c|c|c|c|}
\hline \multicolumn{1}{|c|}{ N= 170 } & Mean & SD & Min. & Max. \\
\hline Coworkers & 17.3 & 2.8 & 11 & 24 \\
\hline Supervision & 14.9 & 3.7 & 5 & 23 \\
\hline Nature of work & 13.2 & 4.5 & 4 & 24 \\
\hline Operating conditions & 12.4 & 3.7 & 6 & 22 \\
\hline Communication & 12.2 & 3.5 & 4 & 20 \\
\hline Contingent rewards & 10.5 & 3.3 & 4 & 18 \\
\hline Pay & 9.6 & 3.1 & 4 & 20 \\
\hline Promotion & 9.4 & 3.9 & 4 & 19 \\
\hline Fringe Benefits & 9.3 & 3.4 & 4 & 20 \\
\hline Total satisfaction & 108.9 & 16.6 & 62 & 145 \\
\hline Work related affective wellbeing score & 59.3 & 7.5 & 34 & 89 \\
\hline
\end{tabular}

Table 3: Percentage of job satisfaction and its different subscales:

\begin{tabular}{lllll}
\hline The Egyptian Journal of Community Medicine & Vol. 36 & No. 3 & July & 2018
\end{tabular}




\begin{tabular}{|l|c|c|c|c|c|c|}
\hline \multirow{2}{*}{} & \multicolumn{2}{|c|}{ Dissatisfied } & \multicolumn{2}{|c|}{ Neutral } & \multicolumn{2}{c|}{ Satisfied } \\
\cline { 2 - 8 } & $\mathbf{N}$ & $\mathbf{\%}$ & $\mathbf{N}$ & $\mathbf{\%}$ & $\mathbf{~ N}$ & $\mathbf{\%}$ \\
\hline Coworkers & 8 & 4.7 & 58 & 34.1 & 104 & 61.2 \\
\hline Supervision & 46 & 27.1 & 67 & 39.4 & 57 & 33.5 \\
\hline Nature of work & 82 & 48.2 & 49 & 28.8 & 39 & 22.9 \\
\hline Operating conditions & 99 & 58.2 & 47 & 27.6 & 24 & 14.1 \\
\hline Communication & 99 & 58.2 & 51 & 30.0 & 20 & 11.8 \\
\hline Promotion & 127 & 74.7 & 35 & 20.6 & 8 & 4.7 \\
\hline Contingent rewards & 120 & 70.6 & 45 & 26.5 & 5 & 2.9 \\
\hline Fringe Benefits & 141 & 82.9 & 24 & 14.1 & 5 & 2.9 \\
\hline Pay & 137 & 80.6 & 32 & 18.8 & 1 & 0.6 \\
\hline Total satisfaction & 81 & 47.6 & 87 & 51.2 & 2 & 1.2 \\
\hline
\end{tabular}

Table (4): Multivariable linear regression analysis for factors affecting total job satisfaction score:

\begin{tabular}{|c|c|c|c|c|c|}
\hline \multirow{2}{*}{ Variables } & \multirow{2}{*}{$\begin{array}{c}\begin{array}{c}\text { Standardized } \\
\text { Coefficients }\end{array} \\
\text { Beta }\end{array}$} & \multirow{2}{*}{$\mathbf{t}$} & \multirow{2}{*}{$\begin{array}{c}P \\
\text { value }\end{array}$} & \multicolumn{2}{|c|}{$\begin{array}{c}95.0 \% \\
\text { Confidence Interval for B }\end{array}$} \\
\hline & & & & $\begin{array}{l}\text { Lower } \\
\text { Bound }\end{array}$ & $\begin{array}{l}\text { Upper } \\
\text { Bound }\end{array}$ \\
\hline Gender* & $-.026-$ & $-.342-$ & .733 & -10.480 & 7.390 \\
\hline \multicolumn{6}{|l|}{ Age $(\text { years) })^{* *}$} \\
\hline $25-$ & .049 & .285 & .776 & $-9.772-$ & 13.066 \\
\hline $30-$ & .239 & 1.601 & .111 & $-2.574-$ & 24.577 \\
\hline $35-$ & .068 & .473 & .637 & -13.374 & 21.794 \\
\hline 40 or more & $-.130-$ & $-.468-$ & .640 & $-27.251-$ & 16.805 \\
\hline Married & .239 & 2.144 & .034 & .867 & 21.146 \\
\hline Divorced/widow & .080 & .707 & .481 & $-8.426-$ & 17.819 \\
\hline 20 or more & .004 & .016 & .987 & $-21.215-$ & 21.562 \\
\hline Diploma & .081 & .943 & .347 & $-3.675-$ & 10.385 \\
\hline Master & .025 & .255 & .799 & $-7.307-$ & 9.474 \\
\hline Fellowship & $-.053-$ & $-.648-$ & .518 & $-20.907-$ & 10.576 \\
\hline 5- $($ years) & $-.236-$ & -2.2 & .028 & $-15.270-$ & $-.879-$ \\
\hline 10- (years) & $-.266-$ & -2.3 & .020 & $-25.719-$ & $-2.284-$ \\
\hline 15- (years) & $-.219-$ & -1.5 & .117 & $-28.763-$ & 3.244 \\
\hline $2000-4000 \mathrm{LE}$ & .002 & .025 & .980 & $-6.052-$ & 6.210 \\
\hline$>4000 \mathrm{LE}$ & .002 & .019 & .985 & $-10.771-$ & 10.985 \\
\hline $\begin{array}{l}\text { Work related } \\
\text { affective } \\
\text { wellbeing score }\end{array}$ & .365 & 4.910 & .000 & .488 & 1.145 \\
\hline $\begin{array}{l}* \text { male is the refe } \\
* * * \text { single is the } 1\end{array}$ & roup & 5 year & re & $\begin{array}{l}\text { group } \\
\text { group }\end{array}$ & \\
\hline
\end{tabular}


Table 5: Multivariable linear regression analysis for factors affecting work related affective wellbeing score

\begin{tabular}{|c|c|c|c|c|c|c|c|}
\hline \multirow{2}{*}{ Variables } & \multicolumn{2}{|c|}{$\begin{array}{c}\text { Unstandardized } \\
\text { Coefficients }\end{array}$} & \multirow{2}{*}{$\begin{array}{c}\begin{array}{c}\text { Standardized } \\
\text { Coefficients }\end{array} \\
\text { Beta }\end{array}$} & \multirow{2}{*}{$\mathbf{t}$} & \multirow{2}{*}{ Sig. } & \multicolumn{2}{|c|}{$\begin{array}{c}95.0 \% \text { Confidence } \\
\text { Interval for B } \\
\end{array}$} \\
\hline & B & SE & & & & $\begin{array}{l}\text { Lower } \\
\text { Bound }\end{array}$ & $\begin{array}{l}\text { Upper } \\
\text { Bound }\end{array}$ \\
\hline Gender ${ }^{*}$ & -.2 & 2.28 & -.00 & -.08 & .929 & $-4.725-$ & 4.317 \\
\hline \multicolumn{8}{|l|}{ Age $^{* * * *}$ (years) } \\
\hline $25-$ & $-.403-$ & 2.829 & $-.027-$ & -.14 & .887 & $-5.993-$ & 5.187 \\
\hline $30-$ & 1.989 & 3.361 & .097 & .592 & .555 & $-4.651-$ & 8.629 \\
\hline $35-$ & 4.840 & 4.355 & .174 & 1.11 & .268 & $-3.765-$ & 13.445 \\
\hline 40 or more & 11.684 & 5.351 & .651 & 2.18 & .031 & 1.111 & 22.257 \\
\hline \multicolumn{8}{|l|}{ Marital status $^{* * * *}:$} \\
\hline Married & .034 & 2.544 & .002 & .01 & .989 & $-4.992-$ & 5.061 \\
\hline $\begin{array}{c}\text { Divorced } \\
\text { widow }\end{array}$ & .774 & 3.257 & .030 & .23 & .812 & $-5.661-$ & 7.209 \\
\hline \multicolumn{8}{|c|}{ Level of qualification ${ }^{* * * * *}$ : } \\
\hline Diploma & 2.081 & 1.715 & .112 & 1.21 & .227 & $-1.308-$ & 5.470 \\
\hline Master & 1.932 & 2.051 & .099 & .94 & .348 & $-2.120-$ & 5.985 \\
\hline Fellowship & 2.001 & 3.856 & .046 & .51 & .605 & $-5.618-$ & 9.619 \\
\hline \multicolumn{8}{|c|}{ Years after graduation ${ }^{* * * * * * *}$ : } \\
\hline $5-$ & $-1.862-$ & 1.788 & $-.122-$ & -1.0 & .299 & $-5.395-$ & 1.671 \\
\hline $10-$ & $-4.451-$ & 2.931 & $-.189-$ & -1.51 & .131 & $-10.241-$ & 1.340 \\
\hline $15-$ & $-5.698-$ & 4.011 & -.218 & -1.42 & .157 & $-13.622-$ & 2.226 \\
\hline 20 or more & $-11.772-$ & 5.212 & $-.598-$ & -2.25 & .025 & $-22.069-$ & $-1.475-$ \\
\hline \multicolumn{8}{|l|}{ Income $^{* * * * * * * *}:$} \\
\hline $2000-4000 \mathrm{LE}$ & .243 & 1.546 & .016 & .15 & .875 & $-2.812-$ & 3.299 \\
\hline$>4000 \mathrm{LE}$ & .703 & 2.929 & .034 & .24 & .811 & $-5.084-$ & 6.489 \\
\hline
\end{tabular}

\section{Discussion:}

The reported job satisfaction level was low $(1.2 \%)$ with mean score \pm SD (108.9 \pm 16.6$)$, while an Italian study showed much higher results for nurses' satisfaction $(58.5 \%)^{15}$ and also, low compared to an Egyptian study that was conducted among physicians working in hospitals (38.7\%). ${ }^{16}$ Low satisfaction in PHC physicians in Egypt is a multifactorial subject may be explained by working in institutes with poor facilities, low salaries, defected self-esteem, and low appreciation even from other specialties' physicians and lots of doubtful-value paper work.

The most satisfying subscale was relations with their colleagues $(61.2 \%)$ with mean score $17.3 \pm 2.8$. That was agreed by Abdel-Rahman et al., 2008 who reported satisfaction with team was the most satisfying subscale although we had lower rate compared with them $(85 \%) .{ }^{16}$

However, results was higher than that obtained in an Indian study where satisfaction of relations with team work among health care workers was $(46 \%)^{17}$ 
(Rana, 2014), and in Jordan (Abu Raddaha et al., 2012). ${ }^{18}$

Job satisfaction of physicians with their supervisors was found to be $(33.5 \%)$ with mean score $14.9 \pm 3.7$ that was lower than that reported in another study in Egypt $(61.3 \%)^{16}$, in India $(53.1 \%)^{17}$ (Rana, 2014), and Jordan. ${ }^{18}$ Abu Raddaha and colleagues, 2012)

In the present study, satisfaction with the nature of work was $(22.9 \%)$. Considering family physicians as 2nd degree doctors and lots of paper work may be considered in explanation of their low satisfaction towards their work nature as another Egyptian study that was conducted among other specialties working in hospitals showed much higher results $(44.1 \%)^{16}$ (Abdel-Rahman et al., 2008) and lower than results reported in an Indian study in private and hospitals (79\% and $67.2 \%$ respectively) $^{17}$ (Rana, 2014), However, it was close to a Jordanian study as Nurses reported high satisfaction with the nature of work $^{18}$ (Abu Raddaha et al., 2012).

Satisfaction with operating policies and procedures in this study was $(14.1 \%)$ that was lower than results of an Indian study among nurses in public and private hospitals $(22.8 \% \text { and } 30.6 \%)^{17}$ (Rana, 2014).

Low levels of satisfaction were noticed for communication, promotion, contingent rewards, fringe benefits and pay subscales. Work is one of the domain satisfactions that are considered under the components of subjective well-being ${ }^{19}$ (Uncu et al., 2006). In current study group, physicians with high JAWS score were more satisfied with their job. The work related affective wellbeing score mean was $59.3 \pm 7.5$ that was close to a Turkish study with mean $65.9 \pm 13.6^{19}$ (Uncu et al., 2006).

Among demographic factors that were studied in relation to JAWS score there was significant association between workrelated affective wellbeing score and physicians age with the highest satisfaction for those aging (40 years and above) and years after graduation. In agreement with this result; Uncu et al., 2006 in their study reported a significant negative relation between physicians' age and subjective well-being score. ${ }^{19}$

Physicians' income per month showed no significant association with JAWS score. Other researchers found different results considering income as people who value money more highly than other goals are less satisfied with their standard of living and with their lives ${ }^{20}$ (Richins \& Dawson, 1992). But these issues should be investigated via extensive qualitative studies.

In current study there was no significant relation between gender or marital status with subjective well-being. Similar finding was reported by Uncu et al., 2006. ${ }^{19}$ In contrast to this finding; Robinson, $2003^{(21)}$ demonstrated that women were more prone to job stress and more burnout ${ }^{22}$ Linze et al., 2002.

As a conclusion, primary health care physicians' job related negative emotional perceptions were associated with reactions in terms of stress, anxiety and depression, and further studies that focus on these issues in a qualitative manner are needed. Because primary health care physicians' job related affective well-being matter, they were serving as gate-keepers for the health of the whole nation.

\section{References:}

1. Oshagbemi T (1999). Overall job satisfaction: How good are single vs. multiple-item measures? J Managerial Psychol; 14: 388-403.

2. Spector P.E (1997). Job satisfaction: Application, assessment, causes and 
consequences. Thousand Oaks, CA: SAGE.

3. Misener TR, Haddock KS, Gleaton JU, Ajamieh ARA (1996). Toward an international measure of job satisfaction. Nursing Research.; 45: 87-91.

4. McNeese-Smith DK (1997). The influence of manager behavior on nurses' job satisfaction, productivity and commitment. Journal of Nursing Administration; 27: 47-55.

5. Espeland KE (2006). Overcoming burnout: How to revitalize your career. J Contin Med EducNurs; 37: 178-84.

6. Hosie, P. J. \& Sevastos, P. P. 2010, 'A framework for conceiving of job-related affective wellbeing', Management Revue: The International Review of Management Studies, vol. 21, no. 4, pp. 406-436.

7. Uncu $\mathrm{Y}$, Bayram $\mathrm{N}$ and Bilgel $\mathrm{N}$ (2006). Job related affective well-being among Primary health care physicians. European Journal of Public Health; 17(5): 514-519

8. Al-Eisa IS, Al-Mutar MS, Al-Abduljalil HK (2005). Job Satisfaction of Primary Health Care Physicians at Capital Health Region, Kuwait. Middle East Journal of Family Medicine; 3 (3)..

9. Behamann M, Schmiemann G, Linger H, Kühne, F., Hummers-Pradier E. \& Schneider, N. (2012). Job Satisfaction Among Primary Care Physicians: Results of a Survey. Deutsches Ärzteblatt International, 109(11), 193-200.

10. Kumar R, Ahmed J, Tanseem B and Hafeez A (2013): Job satisfaction among public health professionals working in public sector: US National Library of Medicine. Journal List. Hum Resour. Health V-II; 2013, PMC 355u587, published online: Jan 9, 2013.

11. Abdullah M. Al Juhani, Nahla A. Kishk: Job satisfacti Ron among PHC physiciians and nurses in Al-Madinah.
Community Medicine Department, Faculty of Medicine, Alexandria University. The Journal of the Egyptian Public Health Association (JEPH Ass). Vol. 81 ( 3):u, 2006.

12. Gadallah $\mathrm{M}$, RadyM,SalemB,AbdelazeemO.Job satisfaction of health care providers in Egypt.TheEgy J Community Med.2000;18(4):1-13.

13. Amira Gamal Abdel-Rahman AG, Amany Waleed. M, Farouk F, Meky. Low Job Satisfaction Among Physicians in Egypt.Kor Hek.2008;7(2):91-96.

14. Spector PE. JSS (Job Satisfaction Survey). Department of Psychology. University of South Florida (1994). Website: http:shell.cas-an

15. Sansoni J, De Caro W, Marucci AR, Sorrentino M, Mayner L and Lancia L (2016). Nurse's Job Satisfaction: An Italian Study. Ann Ig; 28:58-61.

16. Abdel-Rahman AG, Abdel-Halim AW, Allam MF and Meky F (2008). Low Job Satisfaction among Physicians in Egypt. Research Gate; 7(2): 91-96.

17. Rana A (2014). Job Satisfaction among Healthcare Employees: An Empirical Analysis. International Journal of Commerce, Business and Management; 3(4): 2319-2828.

18. Abu Raddaha AH, Alasad J, Albikawi ZF, Batarseh KS, Realat EA, Saleh AA and Froelicher ES, (2012). Jordanian nurses' job satisfaction and intention to quit; 25 (3):216-231.

19. Uncu Y, Bayram N and Bilgel $\mathrm{N}$ (2006). Job related affective well-being among Primary health care physicians. European Journal of Public Health; 17(5): 514-519

20. Richins ML and Dawson $\mathrm{S}$ (1992).A consumer values orientation for materialism and its measurement: scale 
development and validation .Journal of Consumer Research; 19:303-316.

21. Robinson GE (2003). Stresses on women physicians: consequences and coping techniques. Depress Anxiety; 17:180-9.
22. Linzer M, McMurray JE, Visser MR (2002). Sex differences in physician burnout in the United States and Netherlands. J Am Med Womens Assoc; 57:191-3. 